\title{
Antibiotic Misuse among Medical Students in Sohag University
}

\author{
${ }^{1}$ Nesreen A. Mohammed and ${ }^{2}$ Youssria Elsayed Yousef \\ ${ }^{1}$ Public health and community medicine, Faculty of Medicine, ${ }^{2}$ Pediatric nursing, Faculty \\ of Nursing, Sohag University, Sohag, Egypt.
}

\begin{abstract}
Background: Antibiotics are commonly used for self-medication due to their rapid effect in alleviating symptoms resulting in serious adverse effects. Medical students are more prone to self-medicate by virtue of their study of medical subjects and because the information needed for self-diagnosis and treatment are easily accessible. Objective: The study was conducted to investigate the pattern of antibiotics misuse among medical students in Sohag university and associated factors. Method: A cross sectional study was conducted among medical students of Sohag University during the academic year 2016-2017. Faculties of Medicine, Pharmacy and Nursing were chosen to be involved in the present study with a sample of 373 students in the fourth year in the selected faculties. A questionnaire was designed to obtain data about sociodemographic variables and antibiotic misuse pattern among the studied medical students. Results: Findings showed that $65.95 \%$ of the participants used antibiotics without doctor's prescription. About one third (32.5\%) selected the antibiotics depending on their own experience. By asking about their opinion about using antibiotics for self-health care, $35.1 \%$ of the participants considered it acceptable and $5.9 \%$ considered it a good practice. None of the studied variables was significantly associated with antibiotics misuse among the participants. Conclusion: Among the medical students in Sohag University, 65.95\% reported that they self-medicate with antibiotics. It is necessary to focus on increasing the awareness about the problem and its adverse effects, with implementing strict measures to prevent dispensing of drugs, especially antibiotics, without doctor's prescription.
\end{abstract}

Keywords: antibiotics, misuse, medical students.

Corresponding author: Nesreen Ali Mohammed, nesreenhammad180@yahoo.com

\section{Introduction}

Self-medication was defined as the selection and use of drugs to treat selfrecognized illnesses or symptoms. ${ }^{1}$ Medications used for self-medication are often known as 'non-prescription' or 'over the counter' and are provided through pharmacies without doctors' prescription. $^{2}$

Antibiotics are among the medications commonly used for self-medication due to their rapid effect in alleviating symptoms. However, antibiotics misuse results in deleterious effects to both the individual and the community outweighing the predicted benefits. ${ }^{3}$ Among these effects, antimicrobial resistance which is a great concern for public health with its impact on increasing health care costs globally. ${ }^{4}$ Studies showed that antibiotics misuse is facilitated by easy access to antibiotics, unawareness about antibiotics and the serious effects of their misuse, poverty, the high cost of medical care, and previous use of antibiotics. ${ }^{5}$

Nevertheless, antibiotics misuse has been reported in general population in both developing and developed countries. ${ }^{6}$ Furthermore, several studies have revealed that the problem is highly prevalent among university students. ${ }^{7-9}$ They are particularly exposed to the Internet and media therefore, they are 
susceptible to a larger threat of pharmaceuticals advertising. ${ }^{6}$

Furthermore, self-medication was shown to be prevalent among medical students and the incidence was high in medical faculties of many countries e.g. South India, Karachi and Egypt. ${ }^{10-12}$

Medical students are more prone to selfmedicate by virtue of their study of medical subjects and because the information needed for self-diagnosis and treatment are easily accessible from drug indices, books, and other medical students. Furthermore, medical students can easily access the drug itself through samples provided by pharmaceutical company's representatives and from pharmacies. ${ }^{10}$ However, during the undergraduate years, medical students are not allowed to prescribe medicines despite their study of the pathophysiology and pharmacology. The problem of selfmedication and antibiotic misuse is of a special importance among medical students as they are the future health care workers so they should be adequately aware about the serious adverse effects of these practices duo to the major role they are supposed to play in educating the patients and the community about antibiotics misuse disadvantages. ${ }^{13}$

Therefore, the present study is conducted to investigate the pattern of antibiotics misuse among medical students in Sohag university and associated factors.

\section{Method}

Study design: The current study is a cross sectional study conducted in two months (October and November) duration during the academic year 201612017 among medical students of Sohag University.

Setting: Sohag University is an independent University located in Sohag governorate on the Eastern Nile bank. The University includes fourteen faculties and faculties of Medicine, Pharmacy and Nursing were chosen to be involved in the current study.
Table (1): Distribution of the studied students according to sociodemographic criteria, faculty, and special habits $\left(N_{.}=373\right)$

\begin{tabular}{|c|c|}
\hline Characteristics & No. $(\%)$ \\
\hline \multicolumn{2}{|l|}{ Gender } \\
\hline Male & 149 (39.9) \\
\hline Female & $224(60.1)$ \\
\hline \multicolumn{2}{|l|}{ Residence } \\
\hline Urban & $226(60.6)$ \\
\hline Rural & $147(39.4)$ \\
\hline \multicolumn{2}{|l|}{ Faculty } \\
\hline Medicine & $134(35.9)$ \\
\hline Pharmacy & $124(33.2)$ \\
\hline Nursing & $115(30.9)$ \\
\hline \multicolumn{2}{|l|}{ Accommodation } \\
\hline Not family related & $100(26.8)$ \\
\hline Family related & $273(73.2)$ \\
\hline \multicolumn{2}{|l|}{ Where did you spend } \\
\hline Urban & $148(39.7)$ \\
\hline Rural & \\
\hline \multicolumn{2}{|l|}{ Parental $\quad$ education } \\
\hline level & $78(20.9)$ \\
\hline Basic & $87(23.3)$ \\
\hline Secondary & $208(55.8)$ \\
\hline University & \\
\hline \multicolumn{2}{|l|}{ Personal habits } \\
\hline Tobacco smoking & $15(4)$ \\
\hline Alcohol & $4(1.1)$ \\
\hline consumption & $84(22.5)$ \\
\hline Physical activity & $270(72.4)$ \\
\hline \multirow{2}{*}{\multicolumn{2}{|c|}{$\begin{array}{l}\text { How difficult is it to } \\
\text { cover attendance at the } \\
\text { university cost? }\end{array}$}} \\
\hline & \\
\hline I'm able to cover it & $251(67.3)$ \\
\hline $\begin{array}{l}\text { without any } \\
\text { problem }\end{array}$ & \\
\hline $\begin{array}{l}\text { It is difficult to a } \\
\text { moderate extent }\end{array}$ & $89(23.9)$ \\
\hline $\begin{array}{l}\text { It is extremely } \\
\text { difficult }\end{array}$ & $24(6.4)$ \\
\hline $\begin{array}{l}\text { My living } \\
\text { expenses are not } \\
\text { met }\end{array}$ & $9(2.4)$ \\
\hline
\end{tabular}

The studied population was composed of students in the fourth year in the three selected medical faculties in Sohag University which covered 756 colleague students in the academic year 2016- 2017. The sample size was 373 students as calculated using OpenEpi program (Version 3.01, Open Source 
Epidemiologic Statistics for Public Health, USA) based on the following assumptions: Prevalence of antibiotic misuse is $41.5 \%$ according to the results of a previous study conducted in Ain Shams University, Egypt among medical students $^{12}$, power as $80 \%$, and confidence interval was set at $95 \%$.

The number of participants from each faculty was chosen by proportional allocation. Accordingly, 134, 124 and 115 students from Medicine, Pharmacy, and Nursing faculties respectively were included and completed the questionnaires.

The sample was selected using clustered random sampling technique based on the classes in the fourth grade of the selected faculties where classes were selected randomly from a list that contains all classes in the fourth grade in each of the three faculties to complete the required number of the students. The total sample composed of all the gathered clustered random samples.

Data collection procedure: After explaining the study aim, questionnaires were distributed to the students who accept to participate in the study, and they were asked to fill them.

Study instrument: The questionnaire used for data collection was consisted of two Figure (1): distribution of the studied

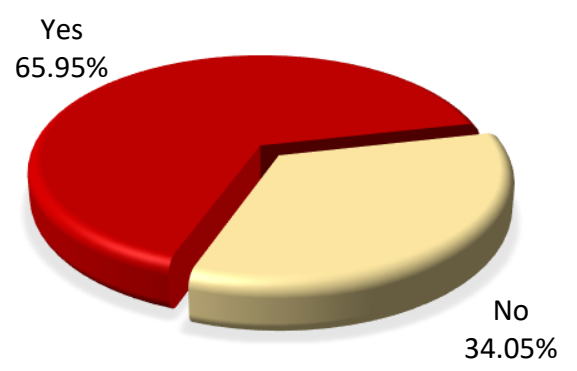

students according to antibiotic misuse $($ No. $=373)$

Table (2): pattern of antibiotic misuse among students ever treated themselves with antibiotics (No.= 246) sections. The first section was designed to collect data including sociodemographic data (age, gender, faculty, residence whether rural or urban and education of the parents). The second section of the questionnaire was based on a pretested validated questionnaire of a previous study ${ }^{14}$, and included inquiries about antibiotic misuse among the studied medical students. A pilot study was conducted on 50 medical students in Faculty of Medicine that had not been included in the study group and the items which were not clearly understood by the students were revised and corrected.

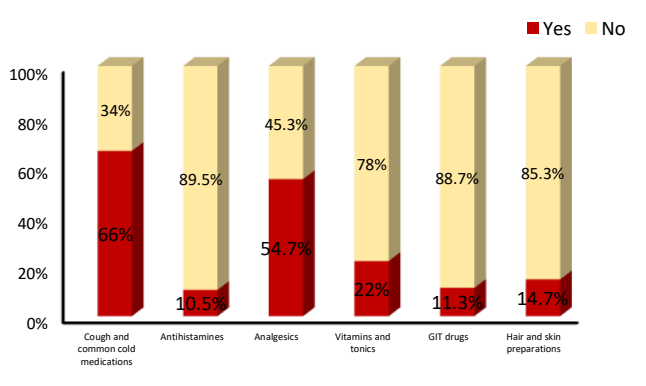

Figure (2): self-medication with other drugs

\section{Statistical analysis}

The statistical analysis was performed using IBM SPSS Statistics for Windows version 22 (IBM Corp., Armonk, NY, USA). Sample characteristics were summarized as numbers and percentage for categorical variables. Chi-Square test was used for comparison between qualitative variables. The associations between antibiotic misuse and the studied determinants were examined using binary logistic regression. A 5\% level was chosen as a level of statistical significance in all statistical tests used in the study.

\section{Ethical consideration}

Ethical approval was secured from Scientific Research Ethics Committee of the Faculty of Medicine, Sohag University. In addition, official approval was secured from the deans of the selected faculties. Informed consent was obtained from each participant after explanation of 


\begin{tabular}{|c|c|}
\hline Questions & No. $(\%)$ \\
\hline \multicolumn{2}{|l|}{ What were the reasons of self-medication with antibiotics? } \\
\hline Poor economic status or cost saving & $20(8.1)$ \\
\hline Previous experience & $73(29.7)$ \\
\hline Simple availability of drugs or convenience & $17(6.9)$ \\
\hline Mild diseases & $94(38.2)$ \\
\hline Good results of treatment by antibiotics & $3(1.2)$ \\
\hline Lack of time & $39(15.9)$ \\
\hline \multicolumn{2}{|c|}{$\begin{array}{l}\text { In the past } 6 \text { months, for how long did you keep using self-medication with antibiotics if } \\
\text { symptoms had not improved? }\end{array}$} \\
\hline One week or less & $119(48.4)$ \\
\hline More than one week & $32(13)$ \\
\hline I don't know. & $95(38.6)$ \\
\hline \multicolumn{2}{|c|}{ For which of the following complaints did you used antibiotics? } \\
\hline Runny nose & $9(3.7)$ \\
\hline Nasal congestion & $19(7.7)$ \\
\hline Cough & $46(18.7)$ \\
\hline Sore throat & $87(35.3)$ \\
\hline Fever & $32(13)$ \\
\hline Vomiting & $2(0.8)$ \\
\hline Diarrhea & $11(4.5)$ \\
\hline Skin wounds & $24(9.8)$ \\
\hline Pain & $16(6.5)$ \\
\hline \multicolumn{2}{|l|}{ Your selection of antibiotics was based on } \\
\hline Recommendation by a pharmacist & $66(26.8)$ \\
\hline Opinion of family members & $33(13.4)$ \\
\hline Opinion of friends & $9(3.7)$ \\
\hline My own experience & $80(32.5)$ \\
\hline Previous doctor's prescription & $57(23.2)$ \\
\hline The advertisement & $1(0.4)$ \\
\hline \multicolumn{2}{|l|}{ What did you consider when selecting antibiotics? } \\
\hline Type of antibiotics & $92(37.4)$ \\
\hline Brand of antibiotics & $2(0.8)$ \\
\hline Price of antibiotics & $11(4.5)$ \\
\hline Indications for use & $126(51.2)$ \\
\hline Adverse reactions & $15(6.1)$ \\
\hline \multicolumn{2}{|l|}{ How did you know the dosage of antibiotics? } \\
\hline By reading the package insert & $89(36.2)$ \\
\hline By consulting a doctor & $3(1.2)$ \\
\hline By consulting a pharmacist & $77(31.3)$ \\
\hline By consulting family members/friends & $10(4.1)$ \\
\hline From the Internet & $7(2.8)$ \\
\hline From my previous experience & $58(23.6)$ \\
\hline By guessing the dosage by myself & $2(0.8)$ \\
\hline \multicolumn{2}{|c|}{ Did you ever change the dosage of antibiotics deliberately during the course of self-treatment? } \\
\hline Always & $31(12.6)$ \\
\hline Sometimes & $103(41.9)$ \\
\hline Never & $112(45.5)$ \\
\hline \multicolumn{2}{|c|}{ Did you ever switch antibiotics during the course of self-treatment? } \\
\hline Always & $19(7.7)$ \\
\hline Sometimes & $118(48)$ \\
\hline Never & $109(44.3)$ \\
\hline \multicolumn{2}{|c|}{$\begin{array}{l}\text { Did you ever check the instructions come with the package insert of antibiotics for self- } \\
\text { treatment? }\end{array}$} \\
\hline Always & $122(49.6)$ \\
\hline Sometimes & $103(41.9)$ \\
\hline Never & $21(8.5)$ \\
\hline \multicolumn{2}{|l|}{ When did you normally stop taking antibiotics? } \\
\hline After a few days regardless of the outcome & $24(9.8)$ \\
\hline After symptoms disappeared & $96(39)$ \\
\hline A few days after the recovery & $38(15.5)$ \\
\hline After antibiotics ran out & $22(8.9)$ \\
\hline At the completion of the course & $63(25.6)$ \\
\hline After consulting a doctor/pharmacist & $3(1.2)$ \\
\hline
\end{tabular}

Table (3): opinion towards self-medication using antibiotics among the participants $($ No. $=373)$ Questions No. $(\%)$

\begin{tabular}{llll}
\hline The Egyptian Journal of Community Medicine & Vol. 38 & No. 4 & October 2020
\end{tabular}




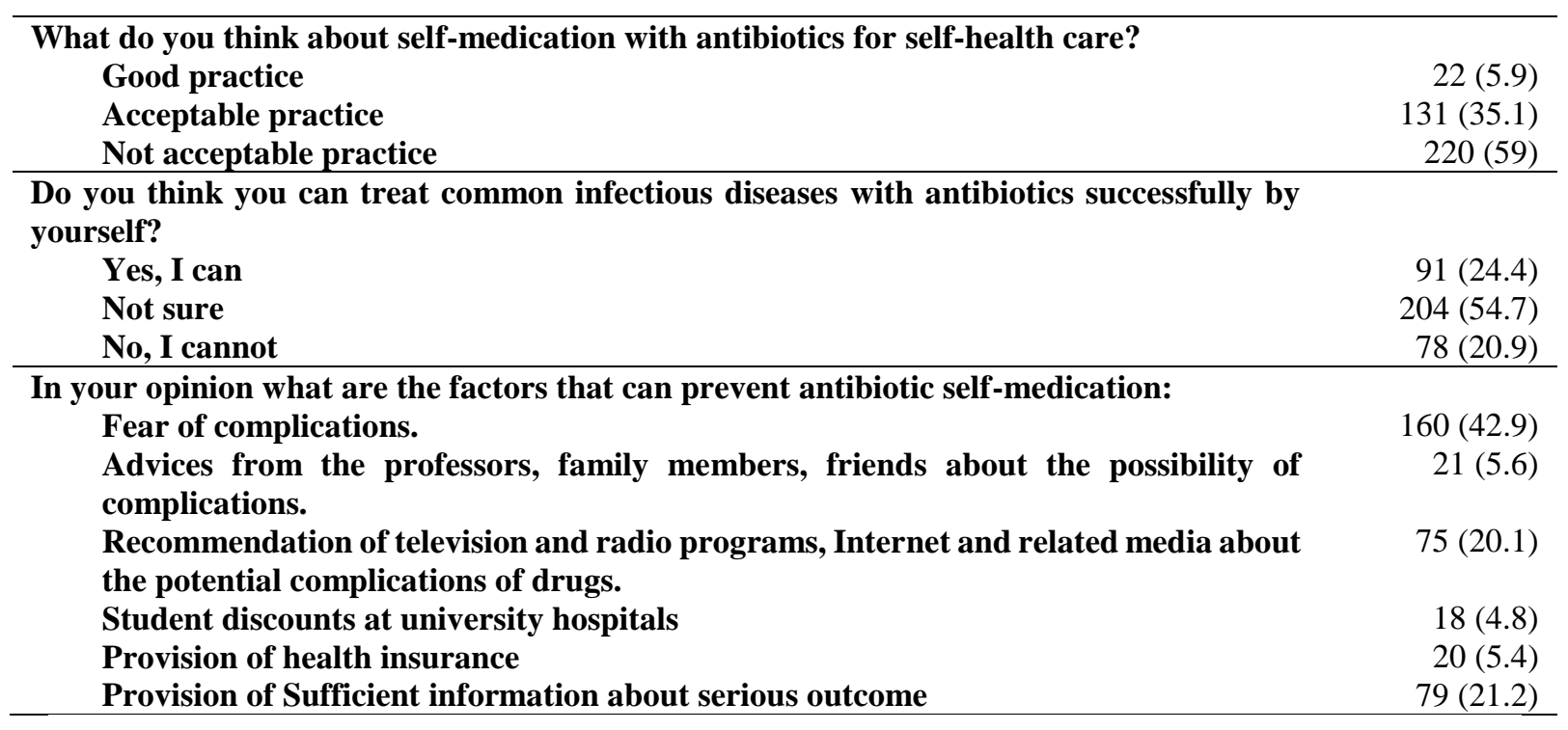

Table (4): comparison between the students in the three studied faculties regarding selfmedication with antibiotics $($ No. $=373)$

\begin{tabular}{|c|c|c|c|c|}
\hline \multirow[b]{2}{*}{ Questions } & \multicolumn{3}{|c|}{ Faculty } & \multirow[b]{2}{*}{ P-value } \\
\hline & $\begin{array}{l}\text { Medicine } \\
(\mathrm{N}=134)\end{array}$ & $\begin{array}{c}\text { Pharmacy } \\
(\mathrm{N}=124)\end{array}$ & $\begin{array}{l}\text { Nursing } \\
(\mathrm{N}=115)\end{array}$ & \\
\hline \multicolumn{5}{|c|}{ Have you ever treated yourself with antibiotics? } \\
\hline Yes & $90(67.2 \%)$ & $84(67.7 \%)$ & $72(62.6 \%)$ & 0.658 \\
\hline No & $44(32.8 \%)$ & $40(32.3 \%)$ & $43(37.4 \%)$ & \\
\hline \multicolumn{5}{|c|}{$\begin{array}{l}\text { What do you think about self-medication with } \\
\text { antibiotics for self-health care? }\end{array}$} \\
\hline Good practice & $6(4.5 \%)$ & $7(5.6 \%)$ & $9(7.8 \%)$ & 0.846 \\
\hline Acceptable practice & $47(35.1 \%)$ & $43(34.7 \%)$ & $41(35.7 \%)$ & \\
\hline Not acceptable practice & $81(60.4 \%)$ & $74(59.7 \%)$ & $65(56.5 \%)$ & \\
\hline \multicolumn{5}{|c|}{$\begin{array}{l}\text { Do you think you can treat common infectious } \\
\text { diseases with antibiotics successfully by yourself? }\end{array}$} \\
\hline Yes, I can & $45(33.5 \%)$ & $31(25 \%)$ & $15(13 \%)$ & $0.003 *$ \\
\hline Not sure & $66(49.3 \%)$ & $70(56.5 \%)$ & $68(59.1 \%)$ & \\
\hline No, I cannot & $23(17.2 \%)$ & $23(18.5 \%)$ & $32(27.9 \%)$ & \\
\hline
\end{tabular}

$P$-value was calculated by Chi-square test $*$ Statistically significant

the study purpose. The questionnaires used were anonymous.

\section{Results}

The current study included 373 students of whom 134 (35.9\%) were from faculty of Medicine, $124(33.2 \%)$ and $115(30.9 \%)$ were from faculties of Pharmacy and Nursing respectively. Regarding gender, $39.9 \%$ of the participants were males and females represented $60.1 \%$. Those who resided in urban areas were $60.6 \%$ and $73.2 \%$ inhabited family related accommodation. More than half $(55.8 \%)$ of students' parents had university education and $67.3 \%$ reported that they could able to cover the cost of attendance at the university easily (table 1).

When asked about antibiotics misuse, about two thirds $(65.95 \%)$ of the participants reported the use of antibiotics without doctor's prescription (Figure 1), and by asking them about self-medication with other drugs in the past six months, $66 \%$ and $54.7 \%$ reported self-medication with

Table (5): Univariate Binary logistic regression analysis about predictors of antibiotics misuse

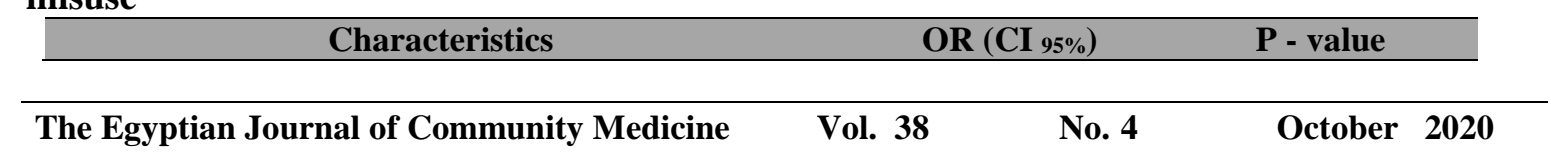




\begin{tabular}{|c|c|c|}
\hline \multicolumn{3}{|l|}{ Gender } \\
\hline Male & 1 & \\
\hline Female & $1.01(0.66-1.57)$ & 0.952 \\
\hline \multicolumn{3}{|l|}{ Residence } \\
\hline Urban & 1 & \\
\hline Rural & $1.11(0.71-1.72)$ & 0.647 \\
\hline \multicolumn{3}{|l|}{ Faculty } \\
\hline Medicine & 1 & \\
\hline Pharmacy & $1.03(0.61-1.73)$ & 0.921 \\
\hline Nursing & $0.82(0.49-1.38)$ & 0.452 \\
\hline \multicolumn{3}{|l|}{ Accommodation } \\
\hline Not family related & $1.13(0.69-1.85)$ & 0.614 \\
\hline Family related & 1 & \\
\hline \multicolumn{3}{|l|}{ Where did you spend most of your life? } \\
\hline Urban & 1 & \\
\hline Rural & $1.19(0.76-1.84)$ & 0.449 \\
\hline \multicolumn{3}{|l|}{ Parental education level } \\
\hline Primary & 1 & \\
\hline Secondary & $1.12(0.59-2.13)$ & 0.718 \\
\hline University & $1.22(0.71-2.09)$ & 0.476 \\
\hline \multicolumn{3}{|l|}{ Personal habits } \\
\hline No & 1 & \\
\hline Tobacco smoking & $2.17(0.59-7.89)$ & 0.239 \\
\hline Alcohol consumption & $0.54(0.08-3.92)$ & 0.545 \\
\hline Physical activity & $1.15(0.68-1.931)$ & 0.609 \\
\hline \multicolumn{3}{|l|}{$\begin{array}{l}\text { How difficult is it to cover attendance at the } \\
\text { university cost? }\end{array}$} \\
\hline I'm able to cover it without any problem & 1 & \\
\hline It is difficult to a moderate extent & $1.31(0.77-2.21)$ & 0.316 \\
\hline It is extremely difficult & $0.64(0.27-1.48)$ & 0.297 \\
\hline My living expenses are not met & $1.89(0.38-9.29)$ & 0.434 \\
\hline
\end{tabular}

cough \& common cold medications and analgesics respectively. More than one fifth $(22 \%)$ reported the use of vitamins and tonics without prescription, $14.7 \%$ used hair and skin preparations, $11.3 \%$ used GIT medications, $10.5 \%$ used antihistamines without doctor consultation (Figure 2).

When asked about the reasons, $38.2 \%$ of the students who practiced self-medication with antibiotics reported that they considered the disease was mild and $15.9 \%$ said that they didn't have time for visiting a doctor. More than one third $(35.3 \%)$ and $18.7 \%$ used antibiotics for sore throat and cough respectively. About one third $(32.5 \%)$ said that the selection of antibiotics they used was based on their own experience and $26.8 \%$ selected the antibiotics according to a pharmacist recommendation. More than one half of them $(51.2 \%)$ and $37.4 \%$ considered indications of use and type when selecting antibiotics respectively and only $6.1 \%$ thought about the adverse reactions. More than thirty six percent reported that they knew the dosage of the antibiotics they used by checking the package insert and $31.3 \%$ knew it by consulting a pharmacist.

More than fifty four percent reported that they intended to change the dosage of the antibiotics they used and when asked about the reasons, $46.3 \%$ changed the dose as the condition worsened, $35.3 \%$ changed it duo to improved symptoms, $9.6 \%$ changed it to reduce adverse reactions and $8.8 \%$ said that the drug was insufficient for completing the treatment. More than fifty five percent reported that they switched antibiotics during the course of selftreatment and most of them (74.5\%) reported that the former antibiotics did not work as a reason, $10.9 \%$ wanted to reduce adverse reactions, $10.2 \%$ said that the 
former antibiotics ran out and 6.6\% reported that the latter one was cheaper. The majority $(91.5 \%)$ reported that they checked the instructions come with the package insert of antibiotics for selftreatment of whom $64 \%$ said that they fully understood them and 39\% reported that they stop taking antibiotics after symptoms disappearance and $25.6 \%$ at the completion of the course (table 2).

By asking about their opinion about using antibiotics for self-health care, $59 \%$ of the participants considered it a non-acceptable practice, $35.1 \%$ considered it acceptable and $5.9 \%$ considered it a good practice. More than half of them reported that they weren't sure if they could treat common infectious diseases with antibiotics successfully by themselves while $24.4 \%$ of them said that they could (table 3). More than one third $(33.5 \%)$ of students of faculty of medicine reported that they are sure of their ability to treat common infectious diseases with antibiotics successfully compared to $25 \%$ of students of faculty of pharmacy and $13 \%$ of nursing students. This difference was statistically significant $(\mathrm{P}$-value $=0.003)($ table 4$)$.

On univariate logistic regression analysis about predictor variables of antibiotics misuse, none of the studied variables was significantly associated with antibiotics misuse among the participants (table 5)

\section{Discussion}

Worldwide, self-medication is considered as an essential part of self-care. ${ }^{15}$ Many people with various characteristics practice self-medication ${ }^{16}$ and among those who practice self-medication, doctors and medical students, also self- medicate, where many studies showed that medical students self-medicate ${ }^{12,17-21}$, and this may be explained by their pharmacological background and their knowledge about diseases and drugs.

With lack of awareness about the deleterious effects of self-medication with drugs especially antibiotics ${ }^{22}$, the ease of accessibility to antibiotics which are commonly dispensed as an over the counter drug, and the spread of the practice among university students and considering that the present medical students will be the future health care workers who are required to inform and educate the public about these risky behaviors and their deleterious consequences, the present study aimed at exploring self-medication with antibiotics among medical students of Sohag university.

The current study revealed that $65.95 \%$ of the participants reported the use of antibiotics without doctor's prescription which is similar to the finding of Jacqueline et $\mathrm{al}^{23}$ who revealed that $65.1 \%$ of the studied students started antibiotics by their selves. These findings are higher than the findings of Lv et $\mathrm{al},{ }^{24}$, El Ezz et al, ${ }^{12}$ and Naveed et al, ${ }^{25}$ who found that $40.2 \%$, $41.5 \%$ and $23 \%$ of the studied students respectively had self-medicated with antibiotics. In contrast, the results of the current study were lower than those of Núñez et al, ${ }^{5}$ where $70 \%$ of the studied university students reported antibiotics selfmedication.

Sore throat and cough were the most common complaints for which the participants used antibiotics which is in line with the findings of many studies ${ }^{7}$, ${ }^{26,27}$ which found that common cold, sore throat and cough were the main complaints the students used antimicrobial agent for.

About one third $(32.5 \%)$ said that the selection of antibiotics they used was based on their own experience and $26.8 \%$ selected the antibiotics according to a pharmacist recommendation. In the study conducted by Afolabi et $\mathrm{al}^{26}, 75 \%$ selected the antibiotic based on a previous experience , $30.2 \%$ based their selection on an advice from doctor, pharmacist or nurse, without a written prescription.

More than fifty four percent of the participants in the current study reported that they intended to change the dosage of the antibiotics they used, more than $55 \%$ reported that they switched antibiotics 
during the course of self-treatment and 91.5\% reported that they checked the instructions come with the package insert of antibiotics for self-treatment and these finding are near those of $\mathrm{Lv}$ et al, ${ }^{24}$ who found that $44.5 \%$ of the students changed antibiotic dosage, $36.5 \%$ switched to another antibiotic and $81.3 \%$ of students read the package insert carefully before taking antibiotics, In another study performed by Okyay et al, ${ }^{28} 93.6 \%$ reported that they checked the instructions come with the package insert of antibiotics which is in agreement with the results of the present study.

According to the present study findings, $39 \%$ reported that they stop taking antibiotics after symptoms disappearance and $25.6 \%$ at the completion of the course. In the study of Okyay et al, ${ }^{28}$ $31.6 \%$ completed the treatment course and $49.3 \%$ stopped treatment after the symptoms had disappeared and the study conducted by Naveed et al, ${ }^{25}$ showed that $83 \%$ of the students reported that they complete the course.

By asking about their opinion about selfmedication with antibiotics for self-health care, $59 \%$ of the participants considered it a non-acceptable practice which is lower than the findings of Jacqueline et $\mathrm{al}^{23}$ where $83.3 \%$ thought that frequent and inappropriate antibiotic use is a serious problem. While, in line with the current study results, Naveed et al, ${ }^{25}$ found that $59 \%$ considered antibiotics misuse a harmful practice.

None of the studied variables was significantly associated with antibiotics misuse among the participants which is in line with the findings of $\mathrm{Lv}$ et $\mathrm{al},{ }^{24}$ who found that most of the studied factors were not significantly related to the practices of antibiotic self-medication. Another study was done by Eticha et $\mathrm{al}^{29}$, gender and age were not associated with antibiotics misuse while residence and monthly pocket money were significantly related to this practice and a study was performed by Wang et $\mathrm{al}^{4}$ showed that residence had significant effect on antibiotic misuse while age, sex and education had no association

\section{Conclusion}

This study highlights that the problem of antibiotics misuse is prevalent among the medical students in Sohag University as $65.95 \%$ of the participants reported that they used antibiotics without doctor's prescription. As the problem of selfmedication especially with antibiotics exerts deleterious impacts, for example but not limited to microbial resistance, and as the present medical students will be the future health care workers who are assigned to combat such harmful behaviors and must be aware of the risks of such practices and educate the public about their serious consequences, it is necessary to focus on increasing their awareness about the problem, its consequences and adverse effects and focusing on their role in guiding patients and directing them to the correct and safe ways to deal with disease conditions. Furthermore, implementing strict measures to prevent dispensing of drugs, especially antibiotics, without doctor's prescription is mandatory. None of the studied variables was significantly associated with antibiotics misuse among the participants.

\section{Study limitations}

The most important limitation is the reliance on self-reporting of the surveyed students which may result in underestimation of the real problem size as they may intend not to declare such data.

\section{References}

1. Jain S, Malvi R, Purviya JK. Concept of self medication: A review. Int $\mathrm{J}$ Pharm Biol Arch. 2011;2(3):831-6.

2. Haroun M, Al-kayali R. Self medication among undergraduate medical students in two universities in Syria. International Journal of Pharmaceutical Sciences and Research. 2017;8(4):1881.

3. Ocan M, Bwanga F, Bbosa GS, Bagenda D, Waako P, Ogwal-Okeng J, et al. Patterns 
and predictors of self-medication in northern Uganda. PloS one. 2014;9(3):e92323.

4. Wang X, Peng D, Wang W, Xu Y, Zhou $\mathrm{X}$, Hesketh T. Massive misuse of antibiotics by university students in all regions of China: implications for national policy. International journal of antimicrobial agents. 2017;50(3):441-6.

5. Núñez $M$, Tresierra-Ayala $M$, GilOlivares F. Antibiotic self-medication in university students from Trujillo, Peru. Medicina Universitaria. 2016;18(73):205-9.

6. Sharif SI, Sharif RS. Antibiotics use with and without a prescription in healthcare students. Amer J Pharmacol Sci. 2013;1:96-9. 7. Suaifan GA, Shehadeh M, Darwish DA, Al-Ije H, Yousef A-MM, Darwish RM. A cross-sectional study on knowledge, attitude and behavior related to antibiotic use and resistance among medical and non-medical university students in Jordan. African Journal of Pharmacy and Pharmacology. 2012;6(10):763-70.

8. Fadare JO, Tamuno I. Antibiotic selfmedication among university medical undergraduates in Northern Nigeria. Journal of public health and Epidemiology. 2011;3(5):217-20.

9. Sarahroodi S, Arzi A, Sawalha A, Ashtarinezhad A. Antibiotics self-medication among southern iranian university students. IJP-International Journal of Pharmacology. 2010;6(1):48-52.

10. Badiger S, Kundapur R, Jain A, Kumar A, Pattanshetty S, Thakolkaran N, et al. Selfmedication patterns among medical students in South India. The Australasian medical journal. 2012;5(4):217.

11. Zafar SN, Syed R, Waqar S, Irani FA, Saleem S. Prescription of medicines by medical students of Karachi, Pakistan: A cross-sectional study. BMC Public Health. 2008;8(1): 162 .

12. El Ezz N, Ez-Elarab H. Knowledge, attitude and practice of medical students towards self medication at Ain Shams University, Egypt. Journal of preventive medicine and hygiene. 2011;52(4).

13. Girish H, Divya H, Prabhakaran S, Venugopalan P, Koppad R, Acharya A. A cross-sectional study on self medication pattern among medical students at Kannur, North Kerala. Journal of Evolution of Medical and Dental Sciences. 2013;2(45):8693-701.
14. Zhu X, Pan H, Yang Z, Cui B, Zhang D, Ba-Thein W. Self-medication practices with antibiotics among Chinese university students. Public Health. 2016;130:78-83.

15. Sherazi BA, Mahmood KT, Amin F, Zaka M, Riaz M, Javed A. Prevalence and measure of self medication: a review. Journal of Pharmaceutical Sciences and Research. 2012;4(3):1774.

16. Shehnaz SI, Khan N, Sreedharan J. Prevalence and practice of self-medication among medical students. GMJ, ASM 2013; 2 (S2): S86-S92.

17. Abay S, Amelo W. Assessment of Selfmedication practices among medical, pharmacy, health science students in Gondar University, Ethiopia. Journal of Young Pharmacists. 2010;2(3):306-10.

18. Badiger S, Kundapur R, Jain A, Kumar A, Pattanshetty S, Thakolkaran N. Selfmedication patterns among medical students in South India. Australas Med J. 2012; 5 (4): 217-20.

19. Pandya RN, Jhaveri KS, Vyas FI, Patel VJ. Prevalence, pattern and perceptions of self-medication in medical students. Int $\mathbf{J}$ Basic Clin Pharmacol. 2013;2(3):275-80.

20. Kumar N, Kanchan T, Unnikrishnan B, Rekha T, Mithra P, Kulkarni V, et al. Perceptions and practices of self-medication among medical students in coastal South India. PloS one. 2013;8(8):e72247.

21. Sontakke S, Bajait C, Pimpalkhute S, Jaiswal K, Jaiswal S. Comparative study of evaluation of self-medication practices in first and third year medical students. Int J Biol Med Res. 2011;2(2):561-4.

22. Virmani S, Nandigam M, Kapoor B, Makhija P, Nair S. Antibiotic use among health science students in an Indian university: A cross sectional study. Clinical Epidemiology and Global Health. 2017;5(4):176-9.

23. Jacqueline N, Sarah N, Micheal B, Samantha K, Norman M, Adriane K. Antibiotic use knowledge and behaviour at a Ugandan University. Int $\mathbf{J}$ Infect Control. 2011;7(4):1-7.

24. Lv B, Zhou Z, Xu G, Yang D, Wu L, Shen Q, et al. Knowledge, attitudes and practices concerning self-medication with antibiotics among university students in western $\mathrm{C}$ hina. Tropical Medicine \& International Health. 2014;19(7):769-79. 
25. Naveed DS, Qamar F, A M, A A, H K, H $\mathrm{M}$, et al. Prevalence and Consequences of Misuse of Antibiotics, Survey Based Study in Karachi2015.

26. Afolabi M, Macarthy L, Osemene K. Use of antimicrobial medicines among university students in Sierra Leone. British Journal of Pharmaceutical Research. 2014;4(1):101.

27. Elagib H. M., Al-Tamimi R. KH., Alolaiqi G. F., Algharbi N. A., Alsamaan B. A., Alsharedah D. N., et al. Irrational Use of Antibiotics among University Students.
International Journal of Science and Research (IJSR). 2016;5(5):848 - 54.

28. Okyay RA, Erdogan A. Self-medication practices and rational drug use habits among university students: a cross-sectional study from Kahramanmaras, Turkey. PeerJ. 2017;5:e3990.

29. Eticha T, Araya H, Asfaw A, Hailu G, Ali D. Prevalence and predictors of selfmedication with antibiotics among Adihaqi Campus students of Mekelle University, Ethiopia2014. 768-684 p. 